\title{
Inovações tecnológicas na relevância da vacinação no combate as doenças imunopreveníveis: um relato de experiência
}

\author{
Technological innovations in the relevance of vaccination in the fight against \\ immunopreventable diseases: an experience report
}

Innovaciones tecnológicas en la relevancia de la vacunación en la lucha contra las enfermedades inmunoprevenibles: un informe de experiencia

Nanni Moy Reis ${ }^{1 *}$, Brenda Favacho Seabra ${ }^{1}$, Joseane Magalhães Almeida ${ }^{1}$, Josiane silva de Moraes $^{1}$, Lucas Vinicius Moraes da Silva ${ }^{1}$, Matheus Barbosa de Oliveira ${ }^{1}$, lanny Ferreira Raiol ${ }^{1}$, Shirley Aviz de Mirandaํㅗㄹ Maria Rute de Souza Araújo.

\section{RESUMO}

Objetivo: Relatar uma ação educativa na qual foi ministrada por meio de tecnologias educacionais sobre a importância da vacinação no combate as doenças imunopreveníveis e as consequências da recusa vacinal, ocorrendo à ação em uma Unidade Básica de Saúde (UBS) no município de Belém. Relato de experiência: Trata-se de uma ação educativa em saúde aplicada em uma Unidade básica de saúde no bairro Águas lindas de Belém-Pa. Tecnologias utilizadas: Apresentação em flip chart e exposição de um mural com imagens de doenças imunopreveníveis. Participaram da ação educativa em média 62 pessoas, entre crianças, adultos, idosos e gestantes. Conclusão: expor aos usuários da unidade básica de saúde a importância da vacinação no combate as doenças imunopreveníveis por meio de inovações tecnológicas de forma clara e sucinta para o melhor entendimento dos usuários para que os mesmos se tornem multiplicadores de tais informações.

Palavras-chave: Educação em saúde, Vacinação, Inovações tecnológicas.

\begin{abstract}
Objective: Report an educational action in which it was taught through educational technologies on the importance of vaccination in combating immunopreventable diseases and the consequences of vaccine refusal, occurring at the action in a Basic Health Unit (BHU) in the city of Belém. Experience report: This is an educational action in health applied in a Basic Health Unit in the neighborhood of Águas lindas de Belém$\mathrm{Pa}$. Technologies used: Flip chart presentation and exhibition of a mural with images of immunopreventable diseases. A total of 62 people participated in the educational action, including children, adults, the elderly and pregnant women. Conclusion: Expose to the users of the basic health unit the importance of vaccination in the fight against immunopreventable diseases through technological innovations in a clear and succinct way to better understand the users so that they become multipliers of such information.
\end{abstract}

Keywords: Health education, Vaccination, Technological innovations.

\section{RESUMEN}

Objetivo: Informar sobre una acción educativa en la que se enseñó a través de tecnologías educativas sobre la importancia de la vacunación en la lucha contra las enfermedades inmunoprevenibles y las consecuencias del rechazo de la vacuna, que tiene lugar en una Unidad Básica de Salud (BHU) en la ciudad de Belém. Informe de experiencia: Esta es una acción educativa en salud aplicada en una Unidad Básica de Salud en

${ }^{1}$ Centro Universitário Metropolitano da Amazônia (UNIFAMAZ), Belém-Pará. *E-mail: moyn941@yahoo.com 
el barrio de Águas lindas de Belém-Pa. Tecnologías utilizadas: presentación de rotafolios y exhibición de un mural con imágenes de enfermedades inmunoprevenibles. Un total de 62 personas participaron en la acción educativa, incluidos niños, adultos, ancianos y mujeres embarazadas. Conclusión: exponer a los usuarios de la unidad básica de salud la importancia de la vacunación en la lucha contra las enfermedades inmunoprevenibles a través de innovaciones tecnológicas de una manera clara y sucinta para comprender mejor a los usuarios para que se conviertan en multiplicadores de dicha información.

Palabras clave: Educación para la salud, vacunación, innovaciones tecnológicas.

\section{INTRODUÇÃO}

Em 1973 foi criado o Programa Nacional de Imunizações (PNI), reconhecido internacionalmente pela sua ampla dimensão, onde a população brasileira tem acesso por meio do Sistema Único de Saúde (SUS), que disponibiliza atualmente 27 tipos de vacinas de forma gratuita. O Brasil por meio da vacinação já erradicou diversas doenças de alcance mundial, como a varíola, sarampo e a poliomielite. No entanto, desde 2013 os índices de cobertura vacinal dessas e outras doenças estão sofrendo queda ano a ano em todas as regiões do país, o que acaba ameaçando a saúde dos brasileiros com o retorno de doenças erradicadas anteriormente (SANSON EM, et al., 2018).

Uma pesquisa epidemiológica realizada no Brasil no período de 2001 a 2016 constatou que 662 crianças menores de um ano adoeceram por difteria, tétano e coqueluche. De acordo com o calendário nacional de vacinação, essas doenças podem ser prevenidas através da vacina pentavalente, que previne também hepatite $B$ e infecções cruzadas pelo Haemophilus influenzae B, devendo ser aplicada a primeira dose ao segundo mês de vida do bebê, a segunda dose ao quarto mês e a terceira dose ao sexto mês (SOUZA BSQ, 2018)

As vacinas são importantes, pois promovem reações imunológicas no organismo do indivíduo sendo desenvolvidas a partir de bactérias e vírus atenuados ou mortos, onde produzirá uma reação de memória e o sistema imunológico diante de uma nova invasão produzirá anticorpos específicos contra o antígeno dando uma resposta eficaz evitando assim, que o indivíduo adoeça novamente (NASSARALLA APA, et al., 2019).

A vacinação proporciona imunidade individual e coletiva, impedindo a disseminação de doenças imunopreveníveis, sendo obrigatório nos programas de saúde. A imunização é de baixo custo e maior incontestabilidade capaz de modificar a trajetória da doença e diminuindo a morbidade e mortalidade, proporcionando prevenção, promoção e proteção. Negligenciar o Programa Nacional de Imunizações (PNI) poderá acarretar em óbitos e graves sequelas (MARTINS KM, et al., 2019).

Apesar de ser um investimento em saúde com obtenção de favoráveis custos e efetividade, motivando um grande impacto na saúde, evitando milhões de mortes por ano e elevando a perspectiva de vida, a aceitação das vacinas não é universal. Devido o aumento do número de vacinas e se uso por programas de saúde pública, houve um crescimento na quantidade de pessoas e grupos o qual anunciaram preocupações com a garantia e a necessidade da aplicação das vacinas (MIZUTA AH, et al., 2018).

Movimentos antivacinais são crescentes e não são um evento novo, surgiram no final do século XVIII, logo após a introdução da vacina contra a varíola, nessa época foi obrigatória, e o motivo da revolta da população era considerada uma invasão do próprio corpo. As consequências do movimento antivacinal são o reaparecimento das doenças imunopreveníveis, como o sarampo e coqueluche. Nos estados unidos em 2018, os casos de sarampo ocorreram em muitos indivíduos intencionalmente não vacinados (SATO APS, 2018).

A hesitação vacinal ocorre por vários motivos como, por exemplo: aspectos históricos, socioeconômicos, religiosos, culturais e o medo de possíveis eventos adversos, assim como a informação equivocada da mídia e até mesmo dos profissionais da saúde apresentarem dúvidas sobre a necessidade da aplicação de vacinas. A maior parte da população cumpre o esquema vacinal, mas há o desafio dos que recusam ou retardam a aplicação das vacinas. O Brasil apresenta melhores níveis de confiança nas vacinas, já nos países da Europa, apresentam maiores níveis de respostas negativas sobre a importância, segurança e eficiência das vacinas (SUCCI RC, 2018).Sobre o tema abordado, criou-se a necessidade de formular uma ação educativa para uma 
melhor compreensão do estudo para a população. As ações educativas no âmbito da saúde representam uma prática que compõe uma perspectiva no cuidado da prevenção de doenças, assim entende-se que as ações educativas são relevantes na construção de ideias ao cuidado. (BEZERRA IMP, et al., 2014).

Assim, foram utilizadas tecnologias educativas, com objetivo de explorar de forma didática e clara a importância da vacinação. No cenário da saúde, as tecnologias educacionais constituem o grupo das tecnologias leves. São peças fundamentais na formação do trabalho educativo e o cumprimento do processo de cuidar (CARVALHO DS, et al., 2019).

Desta forma, o objetivo geral é relatar uma ação educativa ministrada por meio de tecnologias educacionais sobre a relevância das vacinas e os riscos da recusa vacinal pela sociedade em uma Unidade Básica de Saúde de Águas lindas no município de Belém-Pa.

\section{RELATO DE EXPERIÊNCIA}

Trata-se de uma ação educativa do tipo relato de experiência sobre a importância da vacinação para o controle das doenças imunopreveníveis, em uma unidade de saúde no município de Belém-Pará. A ação educativa foi realizada na Unidade Básica de Saúde (UBS) localizada no Bairro das Águas Lindas, no município de Belém-Pará. Ocorreu em outubro de 2019. Participaram da ação educativa a Enfermeira responsável da Unidade Básica de Saúde (UBS) em média 62 pessoas que aguardavam na sala de espera, sendo na maioria adultos, idosos e gestantes. A elaboração para as inovações tecnológicas foi através do flip chart e um mural fotográfico. Na qual o flip chart era composto por blocos de papel $40 \mathrm{~kg}$, papéis fotográficos com imagens em cada uma das etapas abordadas, dentre elas, o que eram as doenças imunopreveníveis, a importância e benefícios da vacinação, o movimento antivacinal e as consequências da não vacinação.

Tal tecnologia foi escolhida por ser um instrumento de fácil locomoção e utilização simples, o que facilitou em sua aplicação e interatividade, já que se tratava de um ambiente de constante fluxo de pessoas. É um mecanismo que retém informações com o uso de letras de forma em tamanho legível, cores fortes, e imagens de fácil compreensão e linguagem acessível para os ouvintes. Além disso, para a excelência do seu uso, exige do palestrante domínio e confiança, pois em seu processo de construçao há o uso de esquemas, o que requer do locutor capacidade de transmissão de informações. A segunda tecnologia consistiu na demonstração de um mural com papel fotográfico A4 180g, na sala de espera a qual foram expostas imagens com o intuito de chamar atenção do público alvo, evidenciando doenças imunopreveníveis e suas consequências.

Optou-se pela apresentação em mural de fotos estilo varal com o uso de barbante, uma vez que, é um importante mecanismo de comunicação não verbal na qual trabalha o sentido da visão, fazendo com que os usuários passem a entender não só o que é dito, mas também aprimorando este sentido com intuito de observar os sintomas de doenças imunopreveníveis, sendo multiplicadores de informações pois as imagens são formas viáveis de ensino permitindo a discussão de informações nelas inseridas desenvolvendo conhecimento de forma dinâmica e levando o usuário a interpretação realística de forma impactante sobre o assunto abordado.

Durante as apresentações das tecnologias, foram esclarecidos alguns mitos e verdades com respeito a vacina, como: pessoas gripadas podem tomar vacina?; pessoa alérgica ao ovo pode tomar vacina?; o mercúrio presente nas vacinas causa autismo?; gestantes não devem tomar vacinas? A mulher lactante não deve receber a vacina?; é preciso tomar vacina todos os anos contra a gripe?; a vacina contra a gripe pode causar reações? Após a apresentação foi distribuído brindes como forma de agradecimento pelo tempo e atenção concedidos. Notou-se que grande parte das pessoas presentes relataram ter medo da vacinação, apesar de terem sido vacinadas, porém nem todos possuíam a carteira de vacinação; e houve também relato de pessoas a não adesão do programa nacional de imunização, devido insegurança, conhecimentos empíricos e religiosidade.

Após a apresentação houve uma discussão a respeito dos benefícios das vacinas, em que os usuários apresentavam dúvidas. Surgiram questionamentos sobre nome, idade, períodos, e se seria necessário 
realizar segunda dose da vacina contra o sarampo em virtude do retorno da doença no Brasil após erradicação. Bem como o desconhecimento de algumas doenças e seus sintomas, como coqueluche, rubéola, tétano e a necessidade de imunizar-se contra o vírus da gripe anualmente. Evidenciou-se melhora da percepção do público alvo com relação a relevância da vacinação, tendo em vista a interação dos usuários, sendo notória a aprendizagem, visto que, foi despertado a curiosidade, e esclarecimento de todas as dúvidas correlacionadas a vacinação. A participação dos acadêmicos de enfermagem proporcionou crescimento em nível de informação sobre a importância da vacinação aos usuários atendidos nesta UBS, propiciando aos acadêmicos o desenvolvimento individual e coletivo referente a tecnologias e ações educacionais, enfatizando a relevância da prevenção e promoção na atenção básica de saúde.

\section{DISCUSSÃO}

A vacinação na infância gera medo e receio por parte da mãe, pois ela reflete o sentimento de dor, mas tem a consciência de que este ato é necessário para a criança. (Marques VC, et al. 2019). São vários os fatores que levam a opiniões diversas sobre a grande importância da vacina entre as pessoas, dentre elas sentem o medo de se vacinar relacionados ao medo de agulhas e o receio ao sentir dor, colaborando para o aumento da não vacinação (Pereira JA e Oliveira EJ, 2018)

Adultos e crianças deixam de se vacinar em decorrência de mitos, tais como: a vacinação podendo causar novas doenças; apenas uma boa higienização é fundamental para manter o sistema imune protegido, assim como declaram precaução sobre aplicações e segurança da vacina. Todavia deve ser analisado mediante a recusa vacinal as crenças existentes neste grupo de pessoas como fatores políticos, filosóficos e a facilidade de informações nas mídias, a qual por muitas vezes não condizem com a verdade e reconhecer possíveis falhas nestes conceitos (MIZUTA AH, et al., 2018). As razões existentes que levam a fatores como o medo, se correlacionam com eventos adversos causados pela vacinação, desconfiança sobre as fabricações e seus futuros efeitos no sistema imune, assim como influencias de pessoas do meio social o qual descrevem experiências pessoais, podendo levar a vacinação perder sua importância.

Os mitos presentes existem desde a introdução da vacina, ou seja, desde do inicio se apresentava causas que se justificavam as recusas, causando o aumento de pessoas não imunizadas e por consequência 0 ressurgimento de doenças erradicadas. (Succi RC, 2017) Dentre as vacinas no combate ao sarampo estão: Dupla viral, Tríplice viral e tetra viral. A vacinação contra a sarampo pode ser feita no período de 1 a 49 anos de idade, sendo de 1 a 30 anos duas doses e de 30 a 49 anos uma dose. Devido os elevados casos de sarampo em alguns estados, todas as crianças de seis meses a um ano de idade devem ser vacinadas com a dose extra da vacina para que as mesmas fiquem imunes nesse período, enquanto aguardam o calendário vacinal habitual. Vale ressaltar que a dose extra não exclui a vacinação de rotina, dando continuidade com a primeira dose aos 12 meses e a segunda e última dose aos 15 meses de idade (BRASIL, 2019).

Acerca do tema abordado, foi observado que apesar de haver campanhas de vacinação e divulgação na mídia, o Programa Nacional de Imunização (PNI) não abrange 100\% da população brasileira, desta forma podemos considerar a cobertura vacinal um desafio para os profissionais, porém muitas vezes esses profissionais não estejam capacitados adequadamente, pois foi observada a ausência de educação permanente em saúde (EPS), e essa pode ser uma grande aliada para uma melhoria significativa e transformações das práticas do serviço, além disso, é considerada uma ferramenta transformadora nas práticas de saúde, utilizada como estratégia do Sistema Único de Saúde (SUS) para a formação e o desenvolvimento de profissionais, para enfrentar as dificuldades do sistema, buscando articular a integração entre ensino, serviço e comunidade no cotidiano.

\section{CONSIDERAÇÕES FINAIS}

Constatou-se que é fundamental a existência de ações educativas em saúde, voltadas a população como forma de prevenção e orientação auxiliando no processo saúde-doença. Dessa forma, o objetivo da ação foi alcançado de maneira satisfatória mostrando à população a importância da imunoprevenção. Contudo constatamos que uns quantitativos de usuários possuíam dúvidas sobre tal assunto abordado, porém através 
da ação, foi facilitado o conhecimento e contribuído para o aprendizado e assim tendo o apoio dos participantes para que mais pessoas compreendam a necessidade da imunoprevenção. Ressaltamos que 0 modo de cuidar abrange vários meios e dentre eles estão ações educativas o qual possibilitem métodos criativos para melhor aprendizagem e alcançar benefícios a todos. Deve ser pertinente aos dados apresentados.

\section{REFERÊNCIAS}

1. ALVES MDFS, et al. A história da vacina: uma abordagem imunológica. Mostra cientifica de biomedicina. CEARÁ, $2019 ; 4(1)$.

2. APS LRMM, et al. Eventos adversos de vacinas e as consequências da não vacinação: uma análise crítica. Rev Saude Publica. 2018; 52:40.

3. BALLALAI I, et al. Manual prático de imunizações. 2 ed. São Paulo. A.C. Farmacêutica, 2015.

4. BRASIL. MINISTÉRIO DA SAÚDE. 2019. In: Programa Nacional de Educação Permanente. Disponível em: http://www.saude.gov.br/trabalho-educacao-e-qualificacao/gestao-da-educacao/qualificacao-profissional/40695politica-nacional-de-educacao-permanente-pneps. Acesso em 20 de Out. 2019

5. BRASIL. MINISTÉRIO DA SAÚDE. 20191. In: Vacinação, sobre o programa. Disponível em: http://www.saude.gov.br/saude-de-a-z/vacinacao/sobre-o-programa . Acesso em 20 Out. 2019.

6. BRASIL. MINISTÉRIO DA SAÚDE. 20192. In: Sarampo: sintomas, prevenção, causas, complicações e tratamento. Disponível em: http://saude.gov.br/saude-de-a-z/sarampo. Acesso em 20 Out. 2019.

7. BEZZERA IMP, et al. Professional activity in the context of health education: a systematic review Journal of Human Growth and Development, 2014; 24(3): 255-262.

8. CARVALHO DS, et al. Construção de tecnologia educacional para estomizados: enfoque no cuidado da pele periestoma. Rev Bras Enferm [Internet]. 2019;72(2):447-54.

9. HOCHMAN G. Imunização, vacinas: passado e futuro. REVISTA CIÊNCIA E SAÚDE COLETIVA. $2019 ; 24$ (9).

10. MARINELI NP, et al. conhecimento dos profissionais de enfermagem em sala de vacina: análise da produção cientifica. Rev Univap. São Paulo, 2015; 21 (38): 26-35.

11. MARTINS KM, et al. A importância da Imunização: revisão integrativa. Rev. Inic. Cient. Ext. 2019; $2(2): 96$ - 101.

12. MARQUES VC, et al. A dor necessária da vacinação e suas nuanças - Percepções de familiares. Revista Enfermagem Atual InDerme, 2019; 89 (27).

13. MIZUTA AH, et al. Percepções acerca da importância das vacinas e da recusa vacinal numa escola de medicina. 2018; 1 (9): 34-40.

14. NASSARALLA APA, et al. Dimensões e consequências do movimento antivacina na realidade brasileira. Revista educação em Saúde, 2019; 7 (1).

15. PEREIRA JÁ, OLIVEIRA EJ. Alegações para a recusa da imunização em adulto. 2018. 21 f. Trabalho de Conclusão de Curso (Graduação em Enfermagem) - Universidade Federal de Uberlândia, Uberlândia, 2018; 21 p.

16. SANSON EM, et al. As influências midiáticas na queda dos índices de vacinação no brasil. Revista das semanas acadêmicas da ulbra cachoeira do sul, 2018; 5 (2).

17. SATO APS. Qual a importância da hesitação vacinal na queda das coberturas vacinais no Brasil? Rev. Saúde Pública. 2018; 52:96.

18. SOUZA, BSQ. Epidemiologia dos casos de óbitos pelas doenças imunopreviníveis: Difteria, Tétano e Coqueluche em crianças menores de um ano no brasil entre 2001 a 2016. 2018. 20 f. Trabalho de Conclusão de Curso (Graduação) - Centro universitário de Brasília (UniCEUB), Brasília, 2018; 45 p.

19. SUCCI RC. Vaccine refusal - what we need to know. J Pediatr (Rio Janeiro), 2018; $94: 574$ - 81. 